\title{
Potential for Landing Gear Noise Reduction on Advanced Aircraft Configurations
}

\author{
Russell H. Thomas ${ }^{1}$, Craig L. Nickol ${ }^{2}$, and Casey L. Burley ${ }^{3}$ \\ NASA Langley Research Center, Hampton, VA 23681 USA \\ And \\ Yueping Guo ${ }^{4}$ \\ NEAT Consulting \\ Seal Beach, CA 90740 USA
}

\begin{abstract}
The potential of significantly reducing aircraft landing gear noise is explored for aircraft configurations with engines installed above the wings or the fuselage. An innovative concept is studied that does not alter the main gear assembly itself but does shorten the main strut and integrates the gear in pods whose interior surfaces are treated with acoustic liner. The concept is meant to achieve maximum noise reduction so that main landing gears can be eliminated as a major source of airframe noise. By applying this concept to an aircraft configuration with 2025 entry-into-service technology levels, it is shown that compared to noise levels of current technology, the main gear noise can be reduced by 10 EPNL dB, bringing the main gear noise close to a floor established by other components such as the nose gear. The assessment of the noise reduction potential accounts for design features for the advanced aircraft configuration and includes the effects of local flow velocity in and around the pods, gear noise reflection from the airframe, and reflection and attenuation from acoustic liner treatment on pod surfaces and doors. A technical roadmap for maturing this concept is discussed, and the possible drag increase at cruise due to the addition of the pods is identified as a challenge, which needs to be quantified and minimized possibly with the combination of detailed design and application of drag reduction technologies.
\end{abstract}

\section{Introduction}

I anding gear noise reduction has continued to be a challenge in efforts directed towards achieving the

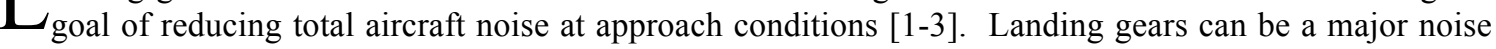
source for subsonic transport aircraft at the approach noise certification point, particularly as engine noise levels are reduced by higher bypass ratio designs. In addition to certification, landing gears must be deployed several miles before touch down for the aircraft to land, and thus, their noise can impact the community well beyond the airport vicinity. Furthermore, the basic components and features of landing gears have remained largely unchanged over the years due to many design requirements that must be met, making it difficult for low noise redesign and application of noise reduction treatments. As a result, landing gear noise represents a barrier to achieving the NASA Aeronautics long term goal of reducing objectionable aircraft noise to within a typical airport boundary.

Most of the landing gear noise reduction research efforts in past years can be characterized as following two major approaches. The first seeks to develop carefully designed add-on fairings or redesign of specific gear components with the goal of modifying the flow structures generated by the multiple components of the landing gear. This approach of relatively minor modifications to existing landing gear designs has certainly seemed to be the most practical and most likely to be implemented, and has been shown to be able to result in about 2 EPNL dB noise reduction for the main landing gears depending on the degree of

\footnotetext{
${ }^{1}$ Senior Research Engineer, Aeroacoustics Branch, MS 461, AIAA Senior Member, Russell.H.Thomas@nasa.gov

${ }^{2}$ Senior Aerospace Engineer, Aeronautical Systems Analysis Branch, MS 442, AIAA Senior Member

${ }^{3}$ Senior Research Engineer, Aeroacoustics Branch, MS 461, AIAA Senior Member

${ }^{4}$ NEAT Consulting, 3830 Daisy Circle, Seal Beach, CA 90740, AIAA Associate Fellow
} 
modifications [4]. The second approach proposes a complete redesign of the gear through subcomponent redesign and rearrangement, aiming at weakening the intensity of the unsteady flows around the gear components, and thus, reducing noise, which can typically result in as much as 7 EPNL dB of noise reduction for the main landing gears [4]. However, even minor modifications to existing landing gear designs require extensive research and design effort, and also face implementation challenges. In the foreseeable future, the utilization of engines with larger diameter and higher bypass ratio for conventional aircraft configurations with engines mounted under the wings will result in the prospect of even longer landing gears, and will only increase the degree of difficulties in implementing either of these approaches to landing gear noise reduction.

The example of commercial aircraft currently in service suggests a third approach to landing gear noise reduction. Most notably, the DC-9/MD-80/MD-90/Boeing 717 series of aircraft have shorter landing gears due to the fact that the engines are mounted on the fuselage rather than under the wings. A key result of the NASA Environmentally Responsible Aviation (ERA) Project has been that a change of aircraft configuration, in addition to advanced technologies, is required in order to achieve the aggressive goals set out by NASA Aeronautics. In fact, the results published [5 and 6] show that aircraft configurations with engines installed over the wings and/or on the fuselage are the concepts that are mostly likely to reach, or even exceed, the goal of 42 EPNL dB cumulative below the Stage 4 requirement. The effects of propulsion airframe aeroacoustic integration, from shielding and reflection of engine noise by the airframe, have been shown to be the single largest differentiator between the engine under-the-wing configurations and the over-the-wing concepts. As part of the final ERA assessment [6], the landing gear noise was predicted with the method of Guo et al. [7], and the impacts of flight speed, gear height, reflection from the airframe, and local flow velocity were all accounted for, depending on the aircraft design. The over-the-wing aircraft concepts have gear heights that are as much as 10 feet shorter, compared to the engine-under-wing types.

This change in configuration to an over-the-wing engine installation type has many significant aircraft system level implications. Among those is the potential to change the installation of the landing gears, and consequently, the potential to reduce landing gear noise. The preliminary study described in this paper begins by highlighting the opportunities for landing gear noise reduction by unconventional aircraft configurations and explores a design path for even further noise reduction beyond that shown with the ERA results. The premise here is to leave the main landing gear itself unmodified, thereby circumventing the implementation challenges that arise with the approaches of modifying the gear itself. The goal is to maximize the noise reduction so that main landing gears can be eliminated as a major source of airframe noise, namely, to reduce its noise to or below the levels of other airframe components. The approach to achieve this goal is to shorten the gear height, integrate the gear into pods in the wing-body join area, design the pod doors to be effective fairings around the gear, and treat the pod doors and surfaces with acoustic liner to reduce reflection to the ground. Because the nose of the pod and doors are non-load bearing and lightweight, the assumption here is that deploying the pod into an effective noise reducing fairing is a more tractable approach compared to modifying the gear itself.

The objective of the preliminary study is to describe the noise reduction concept and to assess its potential. The technical roadmap for developing this concept is also discussed, which reveals many technical challenges, including the effects of the added pods on aerodynamic performance, on the total weight of the aircraft, and on the structural design. The possible drag increase due to the pods at cruise conditions is identified as a major challenge that has to be quantified and minimized in future work.

\section{Reference and N+2 Tube-and-Wing Aircraft Concept Models}

The NASA ERA Project's fuel burn goal is for a reduction of $50 \%$ relative to a best-in-class aircraft in 2005; the noise goal is 42 EPNL dB cumulative below the Stage 4 requirement; and the emissions goal is for a reduction of $75 \%$ in nitrous oxide levels below the CAEP 6 (Committee on Aviation Environmental Protection) standard. The target date is 2020 for key technologies to be at a technology readiness level (TRL) of 4-6 (system or sub-system prototype demonstrated in a relevant environment). This timeline corresponds to a projected aircraft entry into service by 2025 . NASA defines these goals together with the timeframe using the term $\mathrm{N}+2$.

In the final three years of ERA, annual aircraft level system noise assessments have been conducted on a portfolio of aircraft concepts to demonstrate by analysis the performance of the integrated advanced vehicles and technologies compared to the original ERA $\mathrm{N}+2$ goals. The aircraft concepts include a full range of technology assumptions deemed feasible for the 2025 timeframe and incorporate the results of a series of experiments produced by ERA efforts with industry partners throughout the six years of the ERA 
project. Each annual assessment included refined aircraft models and new experimental inputs based on progress to date. Nickol and Haller [5] describe the modeling of the aircraft in detail and also the resulting fuel burn and emissions reduction assessment results at the conclusion of ERA.

This paper focuses on a subset of the ERA vehicle portfolio, aircraft in the Large Twin Aisle (LTA) 301 passenger size class only. In this class and for the $2025 \mathrm{~N}+2$ timeframe, Nickol and Haller [5] modeled a conventional tube-and-wing ( $\mathrm{T}+\mathrm{W})$ configuration and a Mid-Fuselage Nacelle (MFN) configuration. Both configurations were matched with a geared, ultra-high-bypass turbofan (GTF) engine, also with $\mathrm{N}+2$ technology. The MFN is an unconventional tube-and-wing configuration and is distinguished with a double deck fuselage and the engine mounted from the fuselage and positioned at the mid-fuselage location so that the inlet of the nacelle is over the trailing edge of the main wing. The airframe technologies in the ERA vehicles for 2025 included a lighter weight structure enabled by damage arresting composites, natural laminar flow wings (enabled by a Krueger leading edge high lift system) and nacelles, and smaller vertical tails implementing active flow control enhancements. The engine technologies included a low fan pressure ratio with short inlet, swept and leaned fan exit stators, a highly loaded high-pressure compressor enabling higher overall pressure ratios, and a low NOx (oxides of nitrogen) combustor. For comparison, Nickol also modeled a conventional $\mathrm{T}+\mathrm{W}$ aircraft of the same size class with a 2005 technology level as a reference aircraft (Reference 777-200LR-like). Again, the reader is referred to Nickol and Haller [5] for more description of the engine and aircraft modeling and more detailed specifications for the performance and sizing of each of the aircraft, including the reference aircraft.

Table 1 provides the modeling output for the Reference 777-200LR-like aircraft and the T+W301-GTF as reported in Nickol and Haller [5], where TOGW stands for takeoff gross weight and OEW means operating empty weight. The configurations were developed utilizing the rapid geometry modeling tool, OpenVSP [8] and the aircraft sizing and performance analysis tool, FLOPS [9]. These aircraft are required to meet the same 7500 nautical mile mission with the same payload. An output from the aircraft modeling was the low speed flight path at approach, as well as aircraft and engine parameters as a function of the flight path corresponding to the three aircraft noise certification points of sideline/lateral, flyover with cutback, and approach.

Table 1. Vehicle Models for the Reference 777-200LR-like Aircraft and the N+2 T+W301-GTF.

\begin{tabular}{|c|c|c|c|}
\hline & & \multicolumn{2}{|c|}{ Large Twin Aisle } \\
\hline & & $\begin{array}{l}\text { 777-200LR-like (fuel burn } \\
\text { reference) }\end{array}$ & $T+W 301-G T F$ \\
\hline & Units & FLOPS & FLOPS \\
\hline TOGW & $\mathrm{lb}$ & 766,155 & 570,533 \\
\hline OEW & $\mathrm{lb}$ & 341,180 & 270,084 \\
\hline Payload & $\mathrm{lb}$ & 118,100 & 118,100 \\
\hline Passenger Number & & 301 & 301 \\
\hline Range & $\mathrm{nm}$ & 7,500 & 7,500 \\
\hline Total Fuel & $\mathrm{lb}$ & 306,875 & 182,349 \\
\hline Block Fuel & $\mathrm{lb}$ & 277,133 & $\begin{array}{c}164,748 \text { (- 40.6\% relative to } 777- \\
\text { 200LR-like) }\end{array}$ \\
\hline Wing Area & $\mathrm{ft}^{\wedge} 2$ & 5,189 & 4,670 \\
\hline Wing Span & $\mathrm{ft}$ & 225.5 & 226.6 \\
\hline Aspect Ratio & & 9.8 & 11.0 \\
\hline Wing Loading & $\mathrm{lb} / \mathrm{ft}^{\wedge} 2$ & 148 & 122.2 \\
\hline Cruise Mach & & 0.84 & 0.84 \\
\hline Start of Cruise Lift/Drag & & 18.9 & 22.0 \\
\hline Landing Field Length & $\mathrm{ft}$ & 5,312 & 5,594 \\
\hline Thrust per Engine & $\mathrm{lb}$ & 105,824 & 74,000 \\
\hline Fan Diameter & in & 123 & 151.3 \\
\hline
\end{tabular}

\section{Mid-Fuselage Nacelle Aircraft Concept Models}

Three MFN configurations were developed and are described in this section. Table 2 gives the nomenclature and gear configuration information for the three configurations. The baseline configuration is 
the MFN301-GTF concept presented in Nickol and Haller [5]. This configuration utilized a conventional main landing gear design approach, with a wheel track of $27.5 \mathrm{ft}$, a tail strike angle of 12.2 degrees, and a main gear strut compressed length of $9.6 \mathrm{ft}$. The extension of the shock absorber is assumed to add $2.5 \mathrm{ft}$ to the strut length, resulting in an airborne extended main gear length of $12.1 \mathrm{ft}$. This configuration, benefitting from the advanced technologies discussed in Nickol and Haller [5], had an estimated block fuel burn reduction of $46.8 \%$ relative to the $777-200 \mathrm{LR}$ reference case for an identical mission (same range and payload). The short gear configuration, MFN301-GTF-SG, is a modification to the baseline design with the intent of shortening the main gear length to the maximum extent possible without impacting the cruise performance. Tail strike, turn over, tip back, ground clearance, steering, and touch-down constraints were utilized to design the short gear configuration following the guidelines given in Sadraey [10]. The wheel base and aircraft center of gravity location resulted in the nose gear taking $14 \%$ of the load, and the main gear taking the remaining $86 \%$. Tail strike angle was reduced to a minimum value of 10 degrees (aircraft rotates to 7.5 degrees on takeoff), and the wheel track was shortened to $24 \mathrm{ft}$, resulting in a turn over angle of 28.6 degrees (the minimum recommended value is 25 degrees), while accommodating the conventional retraction approach. The resulting compressed gear length was $8.0 \mathrm{ft}$ (10.5 ft uncompressed).

Table 2. Design Objectives for the Baseline MFN and Two Low Noise Configurations.

\begin{tabular}{|c|l|l|c|c|c|}
\hline & Designation & \multicolumn{1}{|c|}{ Configuration } & $\begin{array}{c}\text { Compressed } \\
\text { Main Gear Strut } \\
\text { Length (ft) }\end{array}$ & $\begin{array}{c}\text { Extended Main } \\
\text { Gear Strut } \\
\text { Length (ft) }\end{array}$ & $\begin{array}{c}\text { Retraction } \\
\text { Approach }\end{array}$ \\
\hline Baseline & MFN301-GTF-B & $\begin{array}{l}\text { Concept from ERA Assessment Study, } \\
\text { no changes made }\end{array}$ & 9.6 & 12.1 & Conventional \\
\hline Short Gear & MFN301-GTF-SG & $\begin{array}{l}\text { Gear shortened and moved aft, } \\
\text { fuselage upsweep slightly increased, } \\
\text { tail strike angle reduced }\end{array}$ & 8.0 & 10.5 & Conventional \\
\hline Podded Gear & MFN301-GTF-PG & $\begin{array}{l}\text { Fuselage upsweep significantly } \\
\text { increaesed, gear shortened, gear track } \\
\text { reduced }\end{array}$ & 5.5 & 8.0 & C-17-like \\
\hline
\end{tabular}

The podded gear configuration, MFN301-GTF-PG, is a further modification with the intent of reducing the gear noise further through adopting a C-17 type main gear design approach. This modification includes the addition of sponsons or gear pods to provide maximum gear fairing area and allow the gear track to be reduced so that the gear is retracted into the fuselage mounted sponsons. Figure 1 shows the front view of this concept in the cruise configuration with the main gear pods visible. Compressed gear length was reduced to $5.5 \mathrm{ft}$, requiring a significant increase in aft fuselage upsweep. The wheel track was reduced to $17 \mathrm{ft}$, giving the minimum recommended turn over angle of 25 degrees. This was the shortest gear length and narrowest wheel track distance that met the turn over angle target. The tail strike angle was held to 10 degrees. Clearance between the aft gear door and the ground is a challenge in this configuration, and would need to be addressed in the next design iteration.

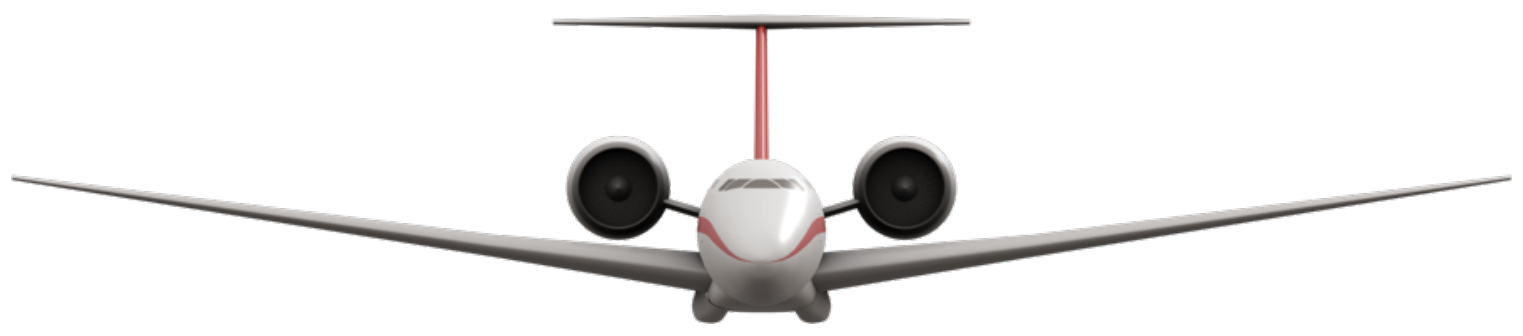

Figure 1. Cruise configuration of all versions of the MFN301-GTF-PG concept, front view.

Implementation of these configurations in FLOPS required the adjustment of the main gear strut length, the addition of the drag increments from the aft fuselage upsweep and sponsons, and the gear location changes for the purposes of center of gravity estimation. Gear length is a direct FLOPS input, and reducing the gear length reduces gear weight, which then ripples through the entire design during the re-sizing process. The aft fuselage upsweep drag increment was estimated using a method from Shevell [11] and input directly into FLOPS. Skin friction drag was added to account for the addition of the sponsons, but 
wave drag and interference drag increases were not estimated. The high cruise speed $(\mathrm{M}=0.84)$ of the MNF301 will pose a significant challenge to designing the sponson OML and fairings to minimize shocks and resulting wave drag. The results shown in Table 3 assume zero additional wave drag and interference drag. A sensitivity study was performed to estimate the impact of varying levels of increased drag.

The reduced gear length in the short gear configuration reduces the baseline OEW by $1899 \mathrm{lb}$, and the overall TOGW by $2455 \mathrm{lb}$. The relative block fuel burn reduction improved slightly from $46.8 \%$ to $47.0 \%$ (this is relative to the 777-200LR-like reference case, see Nickol and Haller [5]). The podded gear configuration has a reduced gear length and weight; however, the added aft fuselage upsweep drag and skin friction drag from the sponson increase fuel burn and result in a similar overall gross weight to the short gear configuration. Block fuel burn reduction degrades to $46.1 \%$ relative to the $777-200$ LR-like reference case. This block fuel burn is optimistic because only the skin friction drag associated with the sponson was included. Figure 2 shows a sensitivity study of block fuel burn vs. overall vehicle drag for the MFN301GTF-PG configuration.

Table 3. Vehicle Models for the MFN Baseline and the Two Low Gear Noise Configurations.

\begin{tabular}{|c|c|c|c|c|}
\hline & & \multicolumn{3}{|c|}{ Large Twin Aisle } \\
\hline & & MFN301-GTF-B & MFN301-GTF-SG & MFN301-GTF-PG \\
\hline & Units & FLOPS & FLOPS & FLOPS \\
\hline TOGW & $\mathrm{lb}$ & 544,747 & 542,292 & 542,837 \\
\hline OEW & $\mathrm{Ib}$ & 262,988 & 261,089 & 258,799 \\
\hline Payload & $\mathrm{Ib}$ & 118,100 & 118,100 & 118,100 \\
\hline Passenger Number & & 301 & 301 & 301 \\
\hline Range & $\mathrm{nm}$ & 7500 & 7500 & 7500 \\
\hline Total Fuel & $\mathrm{Ib}$ & 163,659 & 163,103 & 165,938 \\
\hline Block Fuel & $\mathrm{lb}$ & $\begin{array}{c}147,366 \text { (- } 46.8 \% \text { relative to } 777- \\
\text { 200LR-like) }\end{array}$ & $\begin{array}{c}146,853 \text { (- } 47.0 \% \text { relative to } 777- \\
\text { 200LR-like) } \\
\end{array}$ & $\begin{array}{c}149,508(-46.1 \% \text { relative to } 777 \\
\text { 200LR-like) }\end{array}$ \\
\hline Wing Area & $\mathrm{ft}^{\wedge} 2$ & 4,891 & 4,867 & 4,873 \\
\hline Wing Span & $\mathrm{ft}$ & 208.6 & 208.1 & 208.2 \\
\hline Aspect Ratio & & 11.0 & 11.0 & 11.0 \\
\hline Wing Loading & $\mathrm{lb} / \mathrm{ft}^{\wedge} 2$ & 111.4 & 111.4 & 111.4 \\
\hline Cruise Mach & & 0.84 & 0.84 & 0.84 \\
\hline Start of Cruise Lift/Drag & & 23.8 & 23.8 & 23.3 \\
\hline Landing Field Length & $\mathrm{ft}$ & 5,598 & 5,599 & 5,598 \\
\hline Thrust per Engine & $\mathrm{Ib}$ & 65,500 & 65,000 & 65,500 \\
\hline Fan Diameter & in & 149.2 & 149.2 & 149.2 \\
\hline
\end{tabular}

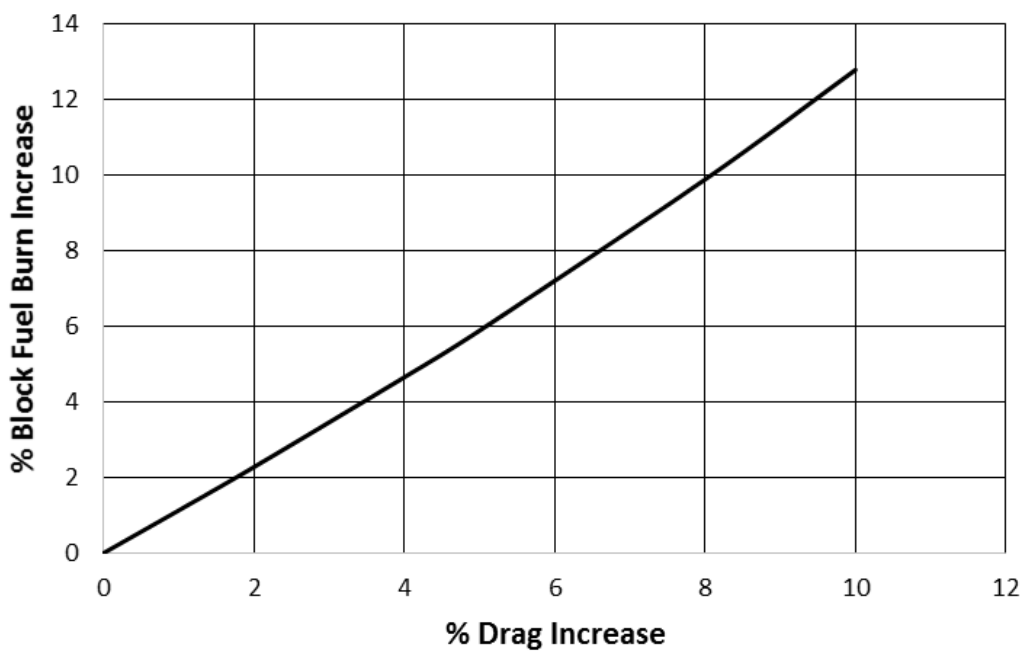

Figure 2. Block Fuel Burn Increase as a Function of Percent Drag Increase. 
As shown in Figure 2, a 5\% drag increase results in a $6 \%$ increase in block fuel burn, and a $10 \%$ drag increase results in a $12.8 \%$ increase in block fuel burn. A good target would be a drag increase of no more than $1 \%$ above the skin friction drag from the addition of the sponsons. The design of a low drag sponson is, therefore, a critical risk area that would need to be addressed in the next design iteration. This would start with the objective of detailed structural and retraction design to integrate the pod with the wing box fairing and minimize the size of the pod. Other approaches to drag reduction should also be investigated including shaping of the pod and the application of drag reduction technologies such as suction, for example. Boundary layer suction on the pod could be an effective approach considering the proximity of the environmental control system intakes that might be utilized for multiple purposes.

\section{Description of Concepts}

Given the premise of this study, the same six-wheel, 777-like main landing gear type and detail is used on the Reference 777-like aircraft, on the T+W301-GTF and all the MFN301-GTF versions. Only the gear height is changed depending on configuration. In this study, the main landing gear does not include the partial main gear fairings or other add-on modifications to the gear itself. With this approach, the gear itself is unmodified therefore reducing the implementation challenges that typically arise from modifications to the existing gear design. In addition, the nose gear is unmodified. Only its strut length changes depending on configuration.

The front view of the 777-200LR-like model optimized with FLOPS as described previously in Section II is shown in Figure 3.

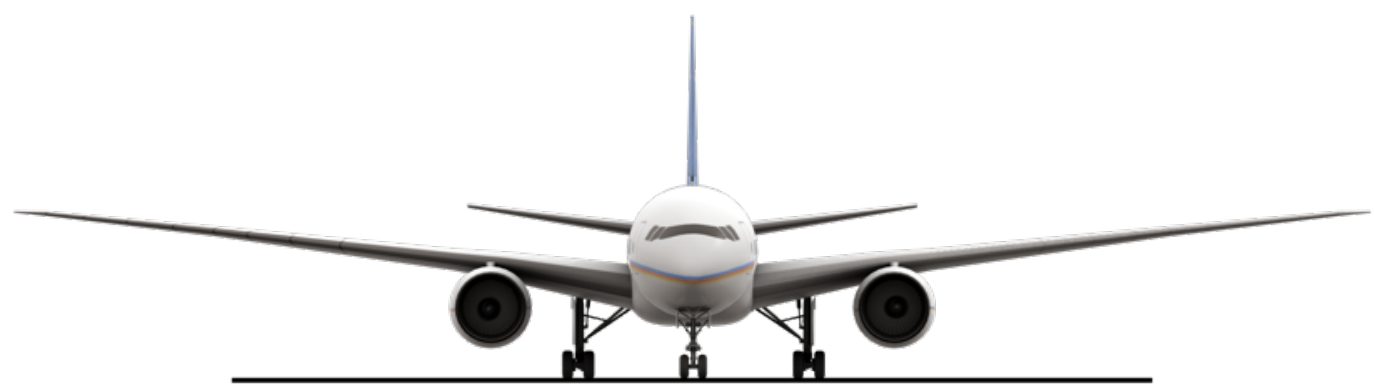

Figure 3. NASA FLOPS optimized 777-200LR-like aircraft concept, front view.

The front view of the T+W301-GTF model (Figure 4) shows the result of the ERA projected changes for an engine-under-wing configuration as a result of the application of a range of 2025 level technology, most notably the larger diameter engine and the resulting longer landing gear.

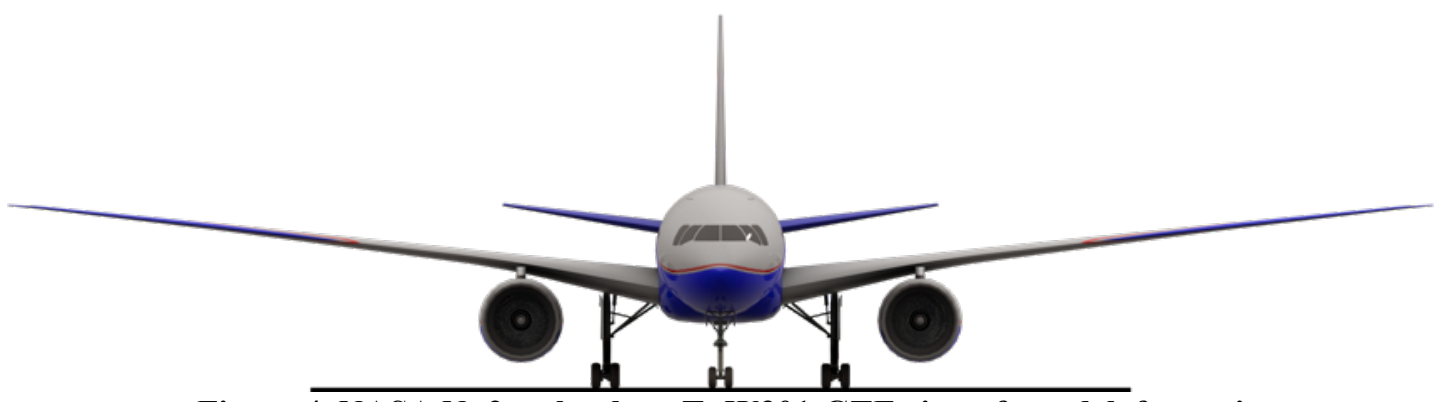

Figure 4. NASA N+2 technology T+W301-GTF aircraft model, front view.

The impact of configuration change to the engine mounted over the wing and at the mid-fuselage position becomes evident in Figure 5, the front view of the MFN301-GTF-B. The gears become shorter and there is a smaller gear track width between the main gears. 


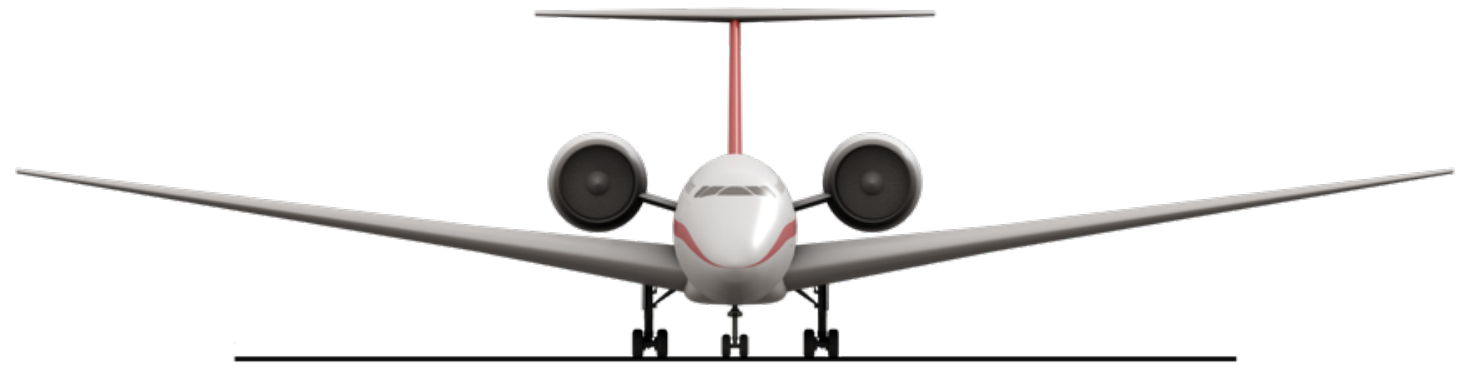

Figure 5. NASA N+2 technology MFN301-GTF-B aircraft model, front view.

The MFN301-GTF-SG concept, Figure 6, shortens the gear to the maximum amount while retaining the same retraction method. The gear track width is reduced to $24 \mathrm{ft}$ from $27.5 \mathrm{ft}$ as discussed in Section III.

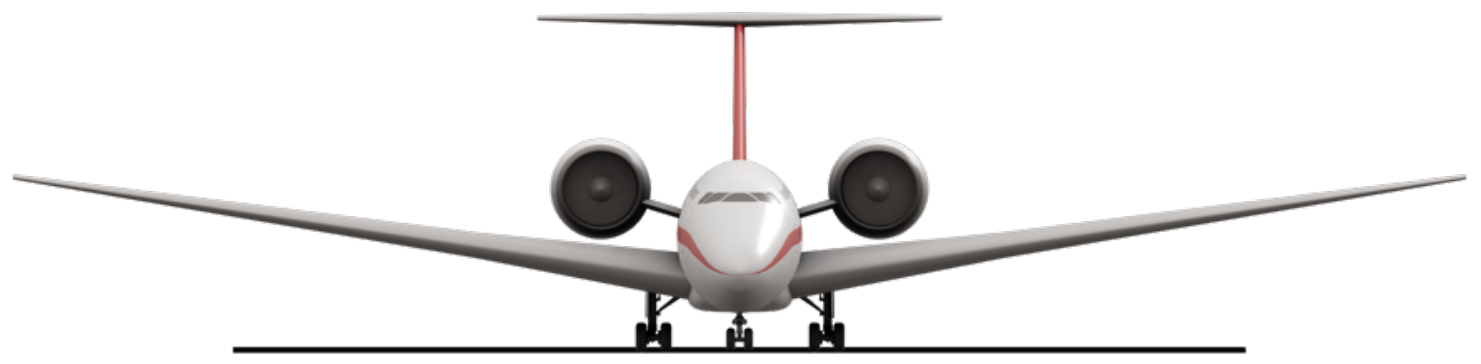

Figure 6. NASA N+2 technology MFN301-GTF-SG aircraft model, front view.

For the next extension along this design path, as described in the previous section, the gear is shortened further, the retraction method is changed, and the gear are stowed into pods or sponsons in the wing box fairing area. The front view of the MFN301-GTF-PG concept is seen in Figure 7 as the aircraft would operate on the ground. As seen in the side view, Figure 8, half of the wheel is visible below the door. The minimum clearance between the fuselage and the ground is $4 \mathrm{ft}$, still more than the minimum clearance seen on the Boeing 717 ( $3 \mathrm{ft}$ ). The noise reduction objective is not just to shorten the main gear strut but also to begin to envelop the gear in the fairing of the pod while the aircraft is on approach. While the aircraft is on approach, the pod deflects the freestream flow around the strut of the main gear. The strut is now in a lower velocity region in the wake of the pod's leading edge nose fairing. However, due to the shock strut, the main gear is extended more while on approach so that the full diameter of the tire is below the door, Figure 9.

Because the pod doors are lightweight, it is reasonable to assume that immediately before touchdown, the nose fairing portion of the pod would retract quickly to a position that allows maximum airflow over the gear for brake cooling. This deployment position is illustrated in Figure 7 and Figure 8 (with the aircraft on the ground) and shows the pod nose fairing retracted, a position that would also be useful for gear inspection and maintenance.

As just described with the MFN301-GTF-PG configuration, the main gear are effectively located inside a cavity formed by the pod doors, the nose pod fairing, and the aft pod fairing. Applying acoustic liner inside this pod cavity to absorb gear noise and minimize reflection of gear noise to the ground below is an additional noise reduction approach that will be designated as MFN301-GTF-PG-L. Because of the position of the gear within the pod the application of acoustic liner is expected to be much more effective in this configuration as compared to the application of acoustic liner to conventional gear installations such as the 777-200LR-like or the T+W301-GTF configurations. The reflection of gear noise from the fuselage and wing is a significant contributor to total main landing gear noise radiated to the ground as recently documented by Guo et al. [7]. 


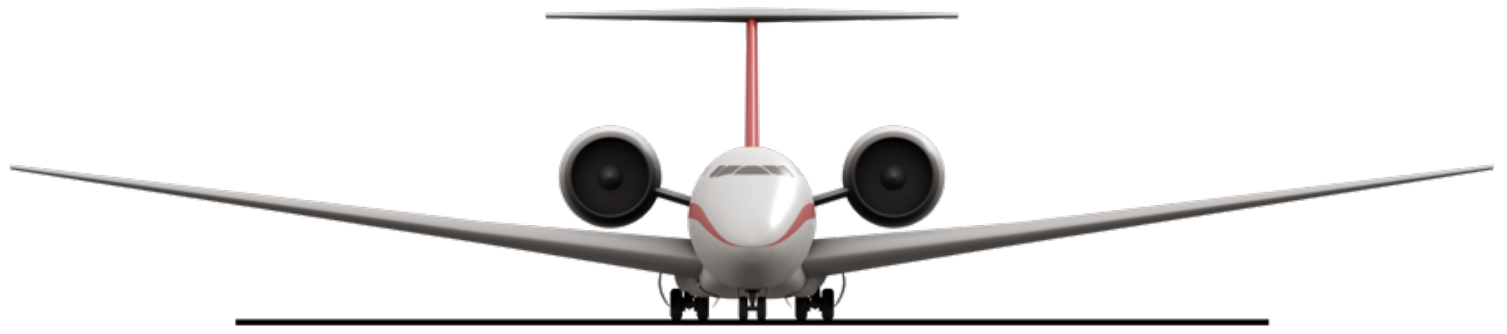

Figure 7. NASA N+2 technology MFN301-GTF-PG aircraft model, front view, with nose fairing portion of the pod retracted.

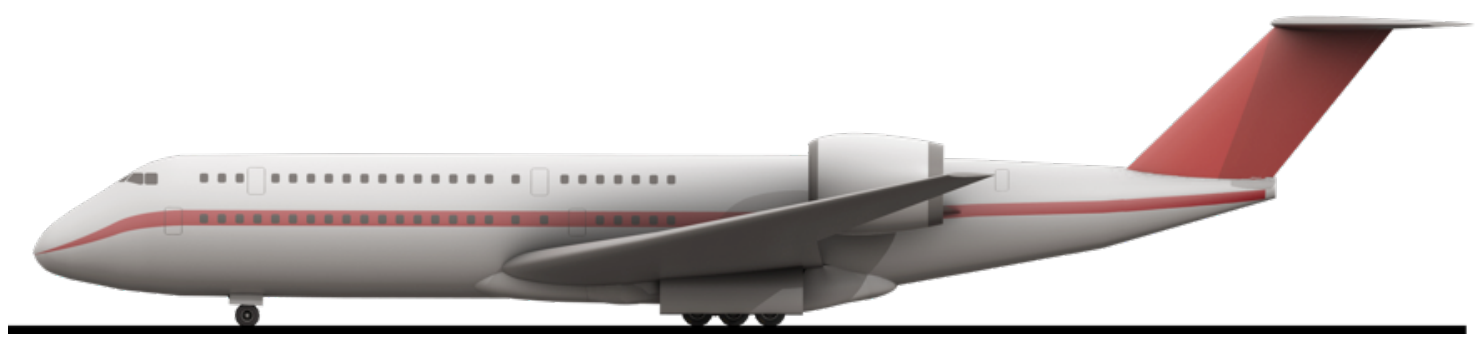

Figure 8. NASA N+2 technology MFN301-GTF-PG aircraft model, side view.

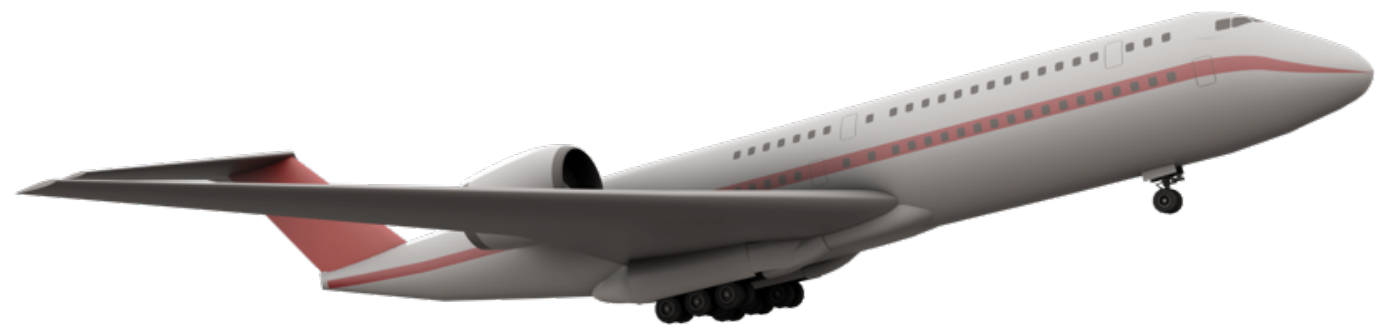

Figure 9. NASA N+2 technology MFN301-GTF-PG aircraft model, on approach, with pod doors and nose fairing both deployed.

The final configuration considered in this study is an extension of these last two versions and is designated the MFN301-GTF-PG-LX. Part of the motivation for all of these concepts is that rather than modifying the gear itself, it is potentially more beneficial to configure, modify, and deploy the pod structure, which is fundamentally thin, lightweight, and potentially multi-fold and even flexible with shape memory alloy actuators. With the complex landing gear doors and retraction mechanisms already on many existing aircraft as examples of possibilities, the final version considered here conceives an additional deployment of the pod nose and pod doors while the aircraft is on approach. As compared to that shown already in Figure 9, this additional deployment extension of approximately $2.5 \mathrm{ft}$ would completely keep the strut within the low velocity region of the pod as well as the top half of the wheels. While on approach, only the bottom half of the wheels would be in the freestream. The acoustic liners inside the pod would be retained. Again, immediately before touchdown, the doors would retract to the more open position to allow for strut compression and brake cooling.

While in cruise, all versions of the MFN301-GTF-PG concept would retract main gear into the pod that is integrated in the wing box fairing region as seen in the front view shown in Figure 1. 


\section{Landing Gear Noise Prediction Results}

The noise metric for the 2025 aircraft models is the certification approach noise as defined in the Code of Federal Regulations (CFR) Title 14, Part 36, which is measured when the aircraft is at 6562 feet from the end of the runway on a 3-degree glide slope with engine power sufficient to abort landing and go around with an eight second engine spool up. In the context of the research and technology maturation of integrated aircraft systems, the noise of ERA aircraft models is predicted according to the same Part 36 rules. The Effective Perceived Noise Level (EPNL) in decibels is predicted for the aircraft landing gear noise. The EPNL $\mathrm{dB}$ is a mathematical formulation that provides a single number characterizing the relevant acoustical effects impacting human perception and annoyance. The EPNL at a certification point includes the integration over time of the tone corrected perceived noise level (PNLT). The tone correction was developed to capture the additional impact of tones on human annoyance. The integration over time begins at a point $10 \mathrm{~dB}$ (in PNLT) below the peak value of PNLT and continues to the point in time when the aircraft PNLT is again $10 \mathrm{~dB}$ below the peak as the aircraft recedes from the certification point. Spherical spreading, atmospheric attenuation, and ground effects are accounted for in the propagation of the aircraft noise to the certification point.

The landing gear noise of the 777-200LR-like is considered as the noise reference for comparison purposes. However, due to the optimization of this aircraft model by FLOPS for the purpose of establishing the fuel burn reference, the characteristics of the aircraft configuration do not represent those of current technologies. Therefore, to establish a gear noise reference, parameters for approach speed, angle of attack, and strut length are chosen to be more representative of current technologies. For the noise prediction, this will be referred to as the 777-200LR-like-CT configuration, for Current Technology.

For the gear noise prediction, several parameters must be established on a consistent basis for each of the configurations, including the gear strut lengths and the disposition of the strut lengths that are within the cavity (inside the fuselage or wing), in the pod low velocity region, and exposed to the freestream, respectively. The major parameters for each configuration are listed in Table 4.

Table 4. Parameters for Main and Nose Landing Gear Component Prediction.

\begin{tabular}{|c|c|c|c|c|c|c|c|c|c|c|c|}
\hline Configuration & $\begin{array}{l}\text { Approach } \\
\text { Speed } \\
\text { (knots) }\end{array}$ & $\alpha$ (degree) & $\begin{array}{c}\text { TOGW } \\
\text { (lbs) }\end{array}$ & $\begin{array}{c}\text { MG Wheel } \\
\text { Track } \\
\text { Width (ft) }\end{array}$ & $\begin{array}{c}\text { MG Strut } \\
\text { Length (ft) } \\
\text { Compressed }\end{array}$ & $\begin{array}{c}\text { MG Strut } \\
\text { Compression } \\
\text { (ft) }\end{array}$ & $\begin{array}{c}\text { MG Strut } \\
\text { Length (ft) } \\
\text { Uncompressed }\end{array}$ & $\begin{array}{c}\text { MG Strut } \\
\text { Length (ft) } \\
\text { Exposed to } \\
\text { Freestream } \\
\end{array}$ & $\begin{array}{l}\text { Cavity Depth } \\
\text { (wing/ } \\
\text { fuselage) (ft) }\end{array}$ & $\begin{array}{l}\text { NG Strut } \\
\text { Length (ft) }\end{array}$ & $\begin{array}{c}\text { NG Strut } \\
\text { Length (ft) } \\
\text { Exposed to } \\
\text { Freestream }\end{array}$ \\
\hline $\begin{array}{l}\text { 777-200LR-like-CT, } \\
\text { Current Technology } \\
\text { Landing Gear Noise } \\
\text { Reference }\end{array}$ & 161 & 4 & 768000 & 36 & 13 & 1.4 & 14.4 & 11.8 & 2.6 & 7.2 & 7.2 \\
\hline $\begin{array}{l}\text { 777-200LR-like (NASA } \\
\text { Optimized FLOPS Fuel } \\
\text { Burn Reference) }\end{array}$ & 132.2 & 10.1 & 766,155 & 36 & 14.5 & 3.0 & 17.5 & 14.4 & 3.1 & 12.2 & 10.0 \\
\hline T+W301-GTF & 138.7 & 3.3 & 570533 & 32 & 16.7 & 2.5 & 19.2 & 15.7 & 3.5 & 13.4 & 11.0 \\
\hline MFN301-GTF-B & 138.7 & 3.8 & 544748 & 27.5 & 9.6 & 2.5 & 12.1 & 9.9 & 2.2 & 8.5 & 6.9 \\
\hline MFN301-GTF-SG & 138.7 & 3.8 & 542292 & 24 & 8 & 2.5 & 10.5 & 8.5 & 2 & 7.4 & 6.1 \\
\hline MFN301-GTF-PG & 138.7 & 3.8 & 542837 & 17 & 5.5 & 2.5 & 8 & \begin{tabular}{|l|}
$2.5 \mathrm{ft}$ freestream, \\
$3.5 \mathrm{ft}$ inside pod \\
\end{tabular} & 2 & 5.6 & 4.6 \\
\hline $\begin{array}{l}\text { MFN301-GTF-PG-L, } \\
\text { Acoustic Liner Inside } \\
\text { the Gear Pod }\end{array}$ & 138.7 & 3.8 & 542837 & 17 & 5.5 & 2.5 & 8 & $\begin{array}{l}2.5 \mathrm{ft} \text { freestream, } \\
3.5 \mathrm{ft} \text { inside pod }\end{array}$ & 2 & 5.6 & 4.6 \\
\hline $\begin{array}{l}\text { MFN301-GTF-PG-LX, } \\
\text { Acoustic Liner Inside } \\
\text { the Gear Pod and } \\
\text { Additional Pod Door } \\
\text { Deployment to Cover } \\
\text { Upper Half of Wheel }\end{array}$ & 138.7 & 3.8 & 542837 & 17 & 5.5 & 2.5 & 8 & $\begin{array}{c}0 \mathrm{ft} \text { (lower half of } \\
\text { the wheel in } \\
\text { freestream flow), } \\
6 \mathrm{ft} \text { inside pod }\end{array}$ & 2 & 5.6 & 4.6 \\
\hline
\end{tabular}

The assessment of the landing gear noise levels is provided by the prediction method detailed in [7]. The noise prediction also utilizes an estimate of the local velocity inside the pod in order to account for the fact that there is still an appreciable level of flow inside the cavity of the pod. The absolute level noise predictions are shown for nose gear, main gear, and total landing gear in Table 5 and again graphically in Figure 10. The same predictions are shown in Table 6 as a change relative to the levels of the 777-like-CT noise level reference and, again, graphically in Figure 11. 
Table 5. Absolute Level Noise Predictions for Nose, Main, and Total Landing Gear. Note: for brevity the engine designation has been dropped for the $\mathrm{N}+2$ aircraft.

\begin{tabular}{|l|r|r|r|}
\cline { 2 - 4 } \multicolumn{1}{c|}{} & \multicolumn{3}{c|}{ EPNLdB } \\
\hline Configuration & Nose Gear & Main Gear & Total Gear \\
\hline 777-like-CT & 79 & 88.8 & 89.3 \\
\hline T+W301 & 74.1 & 85.3 & 85.7 \\
\hline MFN301-B & 74.4 & 83.9 & 84.5 \\
\hline MFN301-SG & 74.5 & 83.7 & 84.3 \\
\hline MFN301-PG & 74.8 & 81.5 & 82.5 \\
\hline MFN301-PG-L & 74.8 & 80 & 81.2 \\
\hline MFN301-PG-LX & 74.8 & 78.8 & 80.4 \\
\hline
\end{tabular}

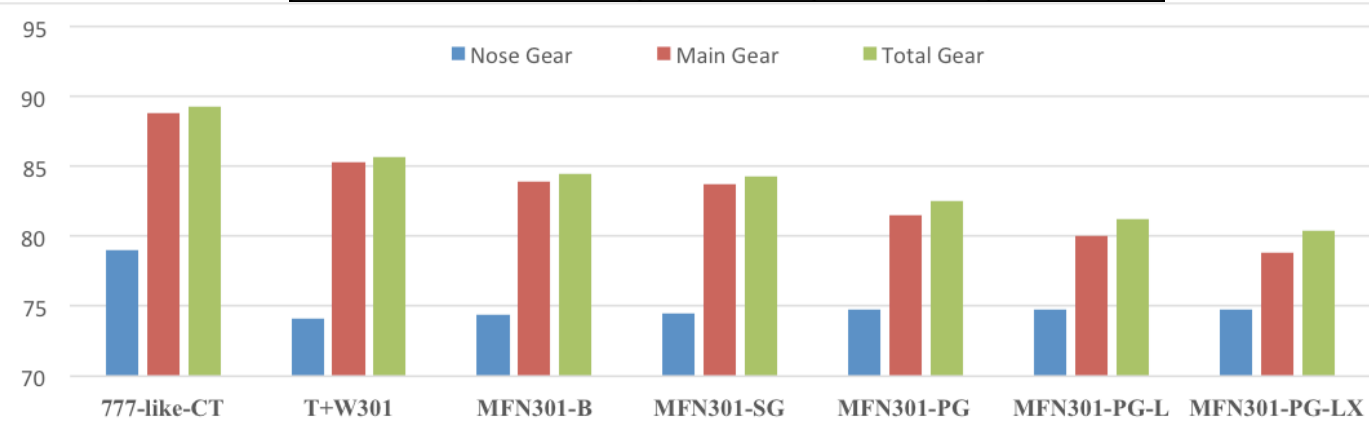

Figure 10. Absolute Level Noise Predictions for Nose, Main, and Total Landing Gear. Note: for brevity, the engine designation has been dropped for the $\mathrm{N}+2$ aircraft.

Table 6. Noise Level Differences Numerically Compared to the Current Technology 777-like Noise Reference Level.

\begin{tabular}{|l|r|r|r|}
\cline { 2 - 4 } \multicolumn{1}{c|}{} & \multicolumn{3}{c|}{ Noise Reduction EPNLdB ref 777-like CT } \\
\hline Configuration & \multicolumn{1}{c|}{ Nose Gear } & \multicolumn{1}{c|}{ Main Gear } & \multicolumn{1}{c|}{ Total Gear } \\
\hline 777-like-CT & 0 & 0 & 0 \\
\hline T+W301 & -4.9 & -3.5 & -3.6 \\
\hline MFN301-B & -4.6 & -4.9 & -4.8 \\
\hline MFN301-SG & -4.5 & -5.1 & -5 \\
\hline MFN301-PG & -4.2 & -7.3 & -6.8 \\
\hline MFN301-PG-L & -4.2 & -8.8 & -8.1 \\
\hline MFN301-PG-LX & -4.2 & -10 & -8.9 \\
\hline
\end{tabular}

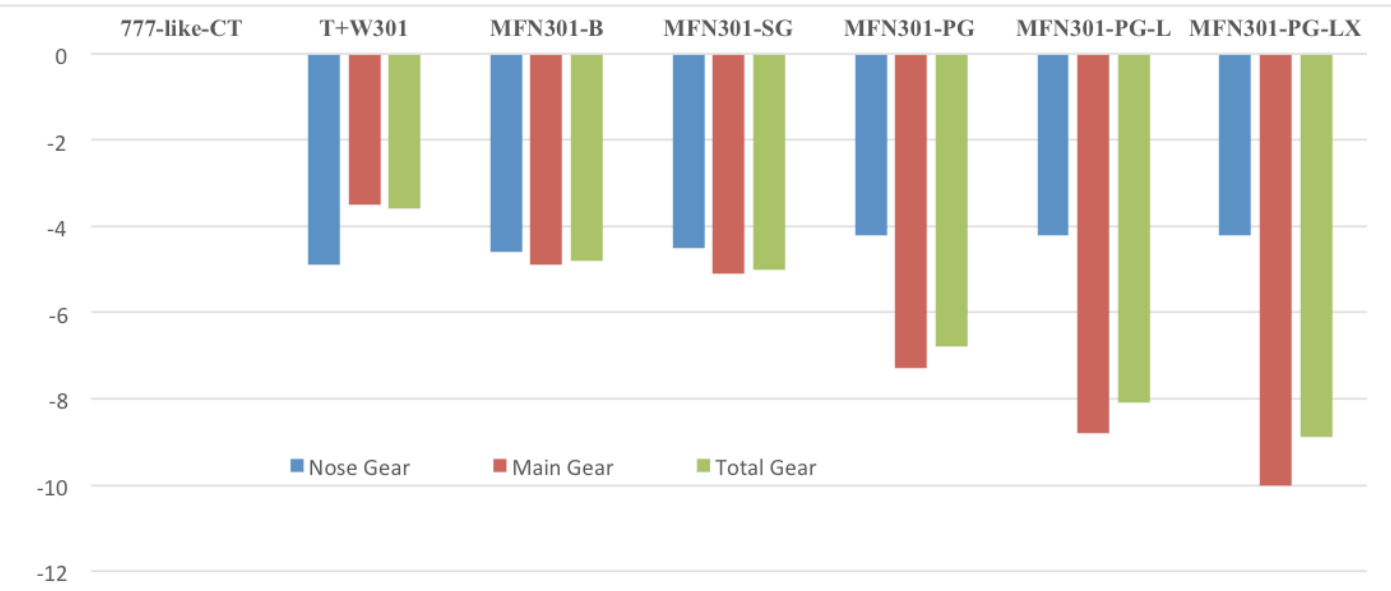

Figure 11. Noise Level Differences Graphically Compared to Current Technology 777-like Noise Reference Level. 
Even though the main landing gear are considerably longer, the main landing gear noise of the T+W301-GTF engine-under-wing aircraft is predicted to be 3.5 EPNL dB lower than the 777-200LR-like due primarily to the reduced approach speed and angle of attack (Table 4). This is a result of the impact of the full range of $\mathrm{N}+2$ technologies on the $\mathrm{T}+\mathrm{W} 301-\mathrm{GTF}$, including lightweight structures and improved low speed aerodynamic performance.

The MFN301-GTF-B shows a further 1.4 EPNL dB reduction in main landing gear noise compared to the T+W301-GTF attributable to the shorter gear and the impact of local flow velocity. It is not attributable to approach velocity because this parameter is equivalent for all $\mathrm{N}+2$ configurations beginning with the T+W301-GTF (Table 4).

The SG configuration results in only an additional 0.2 EPNL dB of reduction due to the fact that the main gear is shortened only an additional $1.6 \mathrm{ft}$ with no other changes to impact the noise relevant parameters. Even so, the prior section also showed an additional reduction in fuel burn of $0.2 \%$, overall an encouraging result.

The real noise reduction potential of the over-the-wing configuration enabling shorter gear begins to be realized with the PG configuration. Main gear noise is reduced an additional 2.2 EPNL dB. As discussed earlier, the addition of the acoustic liner inside the pod is expected to be particularly effective given the position of the gear noise sources inside the pod. The prediction assumes the liner has a $50 \%$ absorption coefficient, and the prediction shows an additional 1.5 EPNL dB of main gear noise reduction. It is noted that the addition of the liner will add a small weight that is not accounted for in this study. And finally, the additional door extension deployment adds another 1.2 EPNL $\mathrm{dB}$ of reduction due to deflecting the freestream flow more completely around the main gear strut.

The total reduction in main gear noise is 10 EPNL dB compared to the 777-200LR-like current technology reference. The nose gear noise has been reduced by $4.2 \mathrm{EPNL} \mathrm{dB}$, compared to the same reference aircraft, through the combination of approach velocity reduction, shorter strut length, and a local velocity effect. Within the group of ERA 2025 aircraft that all benefit from various advanced technologies, the main gear noise reduction is about 6.5 EPNL dB in reference to T+W301-GTF, which all results from the noise reduction concepts discussed here. Considering that there are two main gears to one nose gear, the result of the final MFN301-GTF-PG-LX configuration is that the main gear is effectively close to the noise floor established by the nose gear (Table 5). Furthermore, with this large noise reduction, the main gear would be well below other expected aircraft noise sources in the future.

\section{Conclusions}

Aircraft configurations with engines mounted over the wings offer opportunities to significantly reduce landing gear noise. The exploratory study presented in this paper has shown that innovations in the main landing gear integration with the aircraft can reduce main gear component noise by up to $10 \mathrm{EPNL} \mathrm{dB}$ compared to the same landing gear design on conventional aircraft of current technology, or a reduction of 6.5 EPNL dB compared to main gear noise of ERA aircraft of 2025 technology without the innovation. This innovative approach has been shown to have the potential to reduce the main landing gear noise close to the noise floor as set by the nose gear, and hence eliminate it as a barrier to lowering total aircraft noise at approach conditions.

The technical path to this noise reduction concept has been described in this study, including the integration of the gear into pods in the wing box fairing area. The design concept includes the pod nose to be an effective fairing, the deployment of pod doors to uncover the gear, and the incorporation of acoustic liner inside the pod to minimize noise reflection. Along this technical path, significant challenges exist. One of them is the drag increase at cruise conditions due to the addition of the pods. Further detailed study of this approach is warranted to determine the amounts of the wave drag and the interference drag induced by the pods, and if needed, what technologies are available or can be matured to reduce the drag increase to practically acceptable levels. In such a detailed study, the design of the landing gear pods and the retraction mechanisms will be an integral part, which will determine the shape and minimum dimensions of the pods, as well as the structural requirements and weight impacts. Another critical challenge in maturing this concept is the experimental verification of its noise reduction potential. For such a high-risk and highreward concept, experimental verifications are extremely important in setting the direction of the technology development. This concept is high-risk because of the unconventional integration of gear with the wing and fuselage, however, this concept is also high-reward because of its potential to reduce the noise all way to the noise floor level established by the nose gear. 
If the challenges can be overcome and the technology can be matured for practical application, this concept of podded gears has a significant noise reduction advantage that could benefit many advanced unconventional aircraft configurations, including the mid-fuselage nacelle, truss-braced wing, over-wingnacelle, hybrid-wing-body, and double-bubble concepts. Even traditional configurations with tail mounted engines can benefit from this approach.

As a final prospect, a detailed design study could also reveal if the ultimate version of this concept is possible. That ultimate version (not described or considered in this study) would minimize the size (and the drag) of the pods enough that the gear could be fixed (non-retractable) with the pod doors opening to uncover the gear on approach. In this ultimate version of the pod gear concept, the moving parts would be the lightweight pod doors, this combined with being able to fix the gear could reduce weight, improve safety, and minimize maintenance requirements, all in addition to the noise reduction benefit.

\section{Acknowledgments}

The authors would like to thank both the Environmentally Responsible Aviation Project and the Aircraft Noise Reduction Sub-Project of the Advanced Air Transport Technology Project for supporting this research. The Advanced Concepts Laboratory, AMA Studios, is thanked for their work on the artist renderings of the aircraft concepts.

\section{References}

1. Lockard, D.P. and Lilley, G.M., "The Airframe Noise Reduction Challenge," NASA TM-2004-213013, April, 2004.

2. Elkoby, R., Brusniak, L., Stoker, R.W., Khorrami, M.R., Abeysinghe, A., and Moe, J.W., "Airframe Noise Results from the QTD II Flight Test Program,” AIAA-2007-3457.

3. Dobrzynski, W., "Almost 40 Years of Airframe Noise Research: What Did We Achieve?" Journal of Aircraft, Vol. 47, No. 2, March-April 2010.

4. Dobrzynski, W., Chow, L.C., Smith, M., Boillot, A., Dereure, A., and Molin, N., "Experimental Assessment of Low Noise Landing Gear Component Design," AIAA-2009-3276.

5. Nickol, C.L. and Haller, W.J., "Assessment of the Performance Potential of Advanced Subsonic Transport Concepts for NASA's Environmentally Responsible Aviation Project," $54^{\text {th }}$ AIAA Aerospace Sciences Meeting, AIAA 2016-1030, January, 2016.

6. Thomas, R.H., Burley, C.L., and Nickol, C.L., "Assessment of the Noise Reduction Potential of Advanced Subsonic Transport Concepts for NASA's Environmentally Responsible Aviation Project," AIAA-2016-863.

7. Guo, Y.P., Burley, C.L., and Thomas, R.H., "Landing Gear Noise Prediction and Analysis for Tubeand-Wing and Hybrid Wing Body Aircraft," AIAA-2016-1273.

8. See www.openvsp.org, accessed 3/1/16.

9. McCullers, L., "Aircraft Configuration Including Optimized Flight Profiles," Proceedings of the Symposium of Recent Experiences in Multidisciplinary Analysis and Optimization, NASA CP 2327, April, 1984.

10. Sadraey, M.H., “Aircraft Design: A Systems Engineering Approach,” Wiley, ISBN: 978-1-119-95340-1, November 2012, Chapter 9 - Landing Gear Design, p. 479-544.

11. Shevell, R., "Notes on Drag Analysis," pp. X-11 thru X-13, Stanford University, 1974. 